\title{
All Supply Chains Don't Flow Through: Understanding Supply Chain Issues in Product Recalls
}

\author{
Marjorie A. Lyles, Barbara B. Flynn and \\ Mark T. Frohlich
}

Indiana Universily Kelley School of Business, USA

ABSTRACT Our paper conceptualizes and highlights the role of the supply chains in China's product recall problems. We raise questions about the interrelationships of the focal manufacturer and the supplier firms and the consequences of these relationships. We address some of the causes of the current situation, including a discussion of deep supply chains, the importance of relationships, the role of trust and the impact of cultural misunderstandings. We suggest many future research questions to further understand how the supply chain can cause or deter product recalls.

KEYWORDS China, deep supply chains, product recall, supply chains

\section{INTRODUGTION}

During 2007 and into 2008, every day seemed to bring new stories about product recalls and supply chain invasions by fake or poor quality products - all of which led back to Chinese facilities. These involve a wide range of products such as toothpaste, tainted pet food that caused the deaths of the pets, toy recalls for lead paint and medical product recalls. Sometimes these tainted products result from purposeful counterfeiting. One pharmaceutical firm discovered that a lookalike product was being sold in Canada in place of its real pill. It was discovered that the fake pills crumbled while the real pills did not and after much backwards investigating, this led to a Chinese firm making a copycat product which it sold as the real thing to distributors who then unknowingly put it into pharmacies in Canada. Sometimes the problems are caused by improper manufacturing techniques. An example of this is a baby food manufacturer who bought vitamin supplements from a Chinese producer. The baby food was found to have cement in it. When the baby food manufacturer inspected the Chinese plant, it found that the vitamin supplements were kept in open containers under window sills that were made of 
crumbling cement which would drop particles into the open containers. Sometimes the recalls were no fault of the Chinese supplier. In the summer of 2007, there were recalls of Mattel toys that had design flaws, which consisted of small, high power magnets and a poor design, which allowed the magnets to loosen and be swallowed. Beamish and Bapuji (2008) state that the majority of all toy recalls have been from design flaws. Unfortunately, as a result of these recalls, the popular attitudes toward Chinese-made goods and the perception of China in general has been deteriorating and lowering the levels of trust in Chinese supply chains.

In this paper, we discuss the product recall issue from the perspective of the supply chain. We conceptualize and highlight some of the antecedents and drivers influencing the effectiveness of the supply chains in China and the role they play in the product recalls. This might be perceived as a 'Chinese perspective', but we hope that it is also perceived as a realistic view. We first discuss the globalization of multinational corporations (MNCs) and how this impacts the growth of Chinese supply chains. We raise questions about the interrelationships of the focal manufacturer and the supplier firms and the consequences of these relationships. We discuss some of the issues such as alliances and partnerships, order winners vs. order qualifiers and cultural issues such as guanxi (the granting of preferential treatment to business partners in exchange for favors or obligations). We address some of the challenges involved in deep supply chains, the importance of relationships and the impact of cultural misunderstandings. We finish with a discussion of future research needed to better understand how the supply chain can cause or deter product recalls.

\section{GLOBALIZATION OF MULTINATIONAL GORPORATIONS (MNGs) AND THE GROWTH OF GHINESE SUPPLY GHAINS}

The globalization of MNCs reflects the economic forces that lead to the reorganization of MNCs into more rationalized production structures in various locations (Sideri, 1997). Buckley (2007) explains how the largest MNCs are capable of exploiting the advantages of being in regions with different capital and labour markets. He states 'This regional integration enables costs to be reduced by locating the labour-intensive stages of production in the cheaper labour economies ...' (Buckley, 2007, p. 109). China has benefited from this; with the growth of its productivity has been the growth of local consumption. Furthermore, China has also benefited from the diffusion of knowledge from the MNCs that have formed relationships with local firms and that have invested in state of the art production facilities and technology centres.

China has become the world's manufacturer of many products. It manufactures about 14 percent of the world's $\$ 31 \mathrm{bn}$ market for active drug ingredients, and this percentage is increasing (Zamiska \& Fairclough, 2008). It also manufactures close to 80 percent of the world's toys (Lyles, 2008). Many foreign firms have a two-tier strategy for manufacturing in China: the first tier is to own their manufacturing 
facilities, and the second tier is to outsource some of the manufacturing to their Chinese suppliers. In the case of Mattel, about half of its toys are made in Mattel plants and about half are outsourced to vendor plants. Some of the problems arise when these vendor plants also outsource to other vendor plants and again these other vendor plants may outsource, thus, making the supply chain very long - or 'deep'. The longer the supply chain, the harder it is for the foreign firms to keep track of who did what, when and the final quality of the parts or product (Lyles, 2008).

Nonetheless, international joint ventures and contract manufacturers have been the centres of management training and knowledge exchange. They provide benefits to the manufacturing sector beyond just the monetary exchanges by exposing local management to foreign business practices and competitive markets. However, partnerships in supply chains can vary in terms of the nature of relationships between the focal firm and the supplier firm. At one extreme are spot purchases, where the relationship is purely transactional. At the other extreme are relationships characterized by what is known as 'virtual integration', where the other supply chain member functions almost as a member of the company. For a greater discussion of supply chain integration see Ellram (1990). We use the word 'partner' in this paper to refer to a member of a supply chain.

Partnering can expose local managers to management techniques used in market economies when previously all that was known was central planning. This has led to real contradictions and, possibly, to immature attempts at being competitive with incomplete business models. Level playing fields, transparency, trust and perceptions of fairness may be concepts that are too obscure. Some supply chain issues may be a result of Chinese competitive behaviour without understanding all of the rules by which foreign firms play, or they may be a result of understanding them well enough to identify where the foreign models are vulnerable because firms rely on trust or on reciprocal exchanges and may fall prey to opportunism (Luo, 2006, 2008; Rao, Pearce, \& Xin, 2005).

\section{GAUSES OF PRODUCT REGALLS AND SUPPLY GHAIN ISSUES}

There are at least two reasons that might cause product recalls: (i) manufacture defects in which the product does not conform to specifications; and (ii) design defects in which the product does not meet safety standards. Usually foreign firms design the product and develop procedures for manufacturing the product, standards for quality control and for testing the product. Traceability means that there must be documentation that proves that the supplier has followed the procedures throughout the whole process from the origin to the point of sale. In Chinese supply chains that are deep, it is often difficult to provide the 'traceability' for the product. Other issucs that may affect the supply chains are crossed messages (miscommunication), betrayal of trust, cross-cultural differences in values, relationships and rules of reciprocal exchanges. 


\section{Supply Chains as Alliances}

Generally speaking, foreign partners can potentially support and enhance supply chain success through their provision of both resources (e.g., capital, technical know-how, etc.) as well as their critical guidance in decision-making (Steensma \& Lyles, 2000). However, the role that foreign partners can play in the success of supply chain and firm relationships in transitional economies such as China is complicated somewhat by the dynamic nature of the economic and institutional contexts. Although central planning is now more relaxed in China, the revision of formal rules and informal norms is an incremental and complex process that develops over time (Child \& Czeglédy, 1996). By definition, transitional economies are continuously evolving in terms of their institutions (e.g., political, legal, societal) and factor market conditions.

Research on alliances shows that there are many factors influencing the success of partnerships involved in supply chains. Ultimately, the level of resource support provided by the foreign partner will directly influence the extent to which the supplier firms can learn from the foreign partner (Lyles \& Salk, 1996) and use this knowledge to improve their performance. In general, the more willing and able the foreign firm is to provide support in terms of resources, the greater the opportunity for the supplier to learn and internalize capabilities in these areas (Steensma \& Lyles, 2000). Steensma, Barden, Dhanaraj, Lyles, \& Tihanyi (2008) show that when conflict is present, partners want more control and trust decreases. They affirm that a power imbalance in partnerships does not necessarily lead to dissolution as some have suggested. On the contrary, some unbalanced alliances remain stable over time. What they do find is that the relationship appears to be contingent upon the actions and mindsets created by partner conflict. High levels of knowledge transfer to the venture from the foreign partner combined with high levels of conflict significantly increase the likelihood of the foreign partner wanting more control to protect its investment or its interests. Typically when there is a betrayal of trust, it will lead to conflict. Thus, partner conflict and associated beliefs about the fairness and trustworthiness of the ongoing exchange determine the effect that power differentials have on performance. For example, some foreign firms complain that even when they spend resources to train their partners, the Chinese partners are 'stubborn' and accept the support but do not implement the changes. Thus, to make a relationship work, more than technical skills are needed. This suggests that failure in supply chains must consider technical as well as relational factors.

\section{Confusion of Order Winners and Order Qualifiers}

Hill (2000) defines an order winner as the attribute of a product that wins customer orders. In contrast, an order qualifier is an attribute that must be satisfied for a product to even be considered for purchase by a customer. In supply chains, some 
firms make the mistake of focusing only on their order winners, while neglecting their order qualifiers. However, order qualifiers are equally important. A product whose order qualifiers are neglected will have a difficult time winning the order because it won't be part of the consideration set. Attributes that are commonly considered both as order winners and order qualifiers include price, quality, reputation, availability and previous experience with delivery reliability and speed.

US companies using Chinese suppliers tend to be very clear that they have selected their suppliers based on the supplier's ability to provide a low price for their components. Thus, price is the order winner for components that are ordered from the Chinese supply chains. However, there may have been no discussion of order qualifiers, and it may not be clear to the Chinese suppliers that one of the important order qualifiers is product safety. Thus, from the perspective of the US purchasing company, it seeks the lowest cost component that meets several other criteria, including product safety. However, from the perspective of the Chinese supplier, the only message that is heard is 'low price'. Therefore, because of confusion of order winners with order qualifiers, the supplier may honestly believe that their goal is to provide the lowest cost components, no matter what, even if that means taking short cuts in quality or product safety. This may never occur to the US customer, who sees the order qualifiers as obvious even if it has not been explicitly discussed. It is incumbent upon the purchasing companies to make it clcar to their Chinese suppliers that quality and product safety are not to be sacrificed in the name of low price. Of course, there is the possibility that some suppliers may in fact be dishonest and submit false data back to the purchaser.

\section{Trust}

Trust is a very important component of the relationships in supply chains. Trust means the members expect that no single member will be opportunistic or will violate the norms of the relationship. In addition, under conditions of trust, there is an expectation that the partners are capable of performing the tasks expected. It typically builds on shared values. Thus, if one partner trusts the other, there is the 'expectation that parties will make a good-faith effort to behave in accordance with any commitments, be honest in negotiations and not take advantage of the other even when an opportunity to do so is available' (Hosmer, 1995; Roth, Tsay, Pullman, \& Gray, 2008, p. 23). The latter suggest that, in industries where it is difficult to achieve traceability and transparency and where it is difficult, or even impossible, to do complete testing, trust is critical. In deep supply chains, there may not be the close relationships with the foreign partner, so trust may not develop with all suppliers. That may lead to a betrayal of trust, which generally falls into two categories: (i) violation of organizational norms; or (ii) violation of personal expectations. Violations of organizational norms include sabotage, bribery, cspionage, lying, theft and contract violations, among others. The possibility of a 
betrayal of trust through violation of organization norms relates to Luo (2008, p. 187), who states that 'product recall is in part reflective of moral degradation and normlessness'. Personal betrayals of trust would impact the perceptions of the importance of the relationship and, because of the importance of guanxi, can result in significant negative personal and organizational consequences (Elangovan \& Shapiro, 1998). An example of personal betrayal of trust with a tragic ending concerns the Mattel toy recall in which the manager of Lido, a Mattel contract toy manufacturer, was sold lead based paint by one of his close friends. The manager committed suicide as a result of the tainted paint and the toy recalls.

\section{National Gulture Considerations}

Guanxi. China's national culture is very different from the national culture of the USA and is the result of 2,500 years of Confucianism and Taoism. Failing to understand the nuances of Chinese national culture may lead to supply chain problems. One of the key elements to successful business relationships in China is the role of guanxi, the granting of preferential treatment to business partners in exchange for favours and obligations (Chen \& Peng, 2008; Lee, Pae, \& Wong, 2001). Guanxi requires reciprocity among business associates, or the obligation to return a favour (Jiang \& Prater, 2002). If the obligation isn't fulfilled within a short amount of time, social harmony between the managers will be disturbed because the non-reciprocating manager will have lost face (Lee et al., 2001). In the context of a supply chain, respecting and using guanxi appropriately can be critical. For example, if a foreign purchasing manager does not reciprocate with a favour within an appropriate amount of time, his company may become the target for opportunistic behaviour by the supplier. Because guanxi can be transferred through social networks (Batjargal, 2007), the use of China based agents may be essential for foreign buyers to improve supplier relationship and trust (Jiang \& Prater, 2002).

At the heart of guanxi is the national cultural value of collectivism. Chinese national culture is characterized by a preference for tightly-knit social networks, the expectation that in-group members will support each other (Ramaseshan, Yip, \& Pae, 2006) and a strong urge to maintain social harmony and interdependence within the in-group (Lee \& Dawes, 2005). This reinforces the importance of using a China based agent in dealing with Chinese suppliers. Although there is the expectation of support by in-group members, it is coupled with a lack of obligation to those who are not members of the in-group. Thus, it is not uncommon for Chinese suppliers to take advantage of customers who are not perceived as members of the in-group.

Each of these issues will be exacerbated in a deep supply chain. As there are more links in the chain, it is more difficult to know what is going on in each of them. Furthermore, it is also likely that there are hidden links. Thus, the supplier may be outsourcing through several links that are hidden from the customer. This may be true even in the presence of a contract which explicitly prohibits such practices. 
As the number of links and branches increase in a supply chain, it becomes more difficult to communicate the importance of order qualifiers throughout the supply chain, particularly if the point of contact with the customer does not have a good understanding of the order qualifiers. In addition, the emphasis on price as the order winner may become paramount to smaller enterprises which are desperate to win business, at all costs. If this is the case, the supplier who wins the customer's order may substitute some supplies or resources for cheaper versions of them again ignoring the quality qualifier.

However, guanxi and its extended networks may be useful in dealing with deep supply chains. There is trust between members of a guanxi network, which, coupled with respect for referent power, may help to develop supply chains that are very effective. The use of third party assessment and monitoring organizations can be very helpful, but it is critical that they are selected carefully and explicitly trained to accurately monitor the links in a deep supply chain.

Power distance. A second dimension of national culture that is particularly relevant to supply chains in China is power distance, which is the expectation that power is distributed equally (Hofstede, 1980); high power distance is evident in China's pervasive centralized authority and hicrarchical structures (Pun, 2001; Zhou \& Chuah, 2002). Chinese people accept that power is unequally distributed and naturally defer to those they perceive to be their superiors (Ramaseshan et al., 2006), who they expect to be benevolent and treat all people fairly, providing them with stability, close supervision and explicit rules (Pun, 2001). Thus, it is very important that Chinese suppliers are closely supervised and provided with very explicit rules. Unlike suppliers in the USA, Chinese suppliers expect to be very closely supervised. As supply chains become deeper, of course, close supervision is much more difficult. This is exacerbated by language and culture issues when US firms have Chinese suppliers.

Long-term orientation. A third dimension of national culture, long-term orientation, may also be relevant to supply chain issues in China. The construct of long-term orientation traces its roots to Confucian dynamism, which values stability over change (Li, Anderson, \& Harrison, 2003); this is reflected in bureaucracy and difficulty incorporating the voice of the customer ( $\mathrm{Li}$ et al., 2003) as well as in dedication to a lasting guanxi relationship, once established (Mavondo \& Rodrigo, 2001). Traditionally, production quotas in China were determined by the centralized government, not by market forces and many companies still struggle with the need to incorporate the voice of the customer. This long history of reliance on central planning led to passive working behaviour, lack of incentives, poor product quality, bureaucratic bloating and a disregard for market and customer needs $(\mathrm{Li}$ et al., 2003). Given a choice between meeting the production schedule and achieving the customer's desired level of product quality, the production schedule may often win. 


\section{Supplier Ownership}

Joint ventures or wholly foreign-owned companies with investments from the USA and Europe are much more advanced in adopting modern management principles. This is very apparent when visiting new, state of the art factories in southeastern China. Being selected as suppliers to US-owned companies is very important to such firms, both in terms of the business that they bring and in their ability to help the Chinese suppliers learn more about doing business with foreign customers. However, many privately-owned enterprises and some of the collective- and stateowned enterprises are much farther behind in adopting modern management principles. This is partly due to lack of experience dealing with foreign customers, with the associated learning that takes place, as well as to the legacy of central control.

In searching for the lowest cost provider, US customers try to be diligent about these issues. While a smaller privately-owned or state-owned enterprise may make promises and may honestly believe that it is capable of providing the desired level of quality, reality may be quite different. Again, this harkens back to confusion of order winners and order qualifiers; vendor firms may not emphasize enough that it is critical that products must be made according to specifications and that nothing can be done to jeopardize product safety, in addition to providing the products at the lowest price. It is also critical that Chinese suppliers are provided with explicit guidelines and closely monitored.

\section{The Role of Contracts}

In the USA, contracts play a critical role in the establishment and maintenance of supply chain relationships and there is the belief that a good contract will ensure that the customer's specifications will be met. However, contracts are not perceived in the same way in China, whose government does not always actively support contractual provisions. Research on relational governance (Rao et al., 2005) states that in the absence of a facilitative government, informal relationships will be more important than formal contracts. Thus, although a US customer may believe that having a strong contract will ensure that its standards are followed by its Chinese supplier, establishing a strong relationship that is based on guanxi may be more important, according to the Chinese partner.

\section{DEEP SUPPLY CHAINS}

In their simplest sense, supply chains involve a series of partners that, to varying degrees, plan, source, make and deliver their goods and services through a network of companies. In many networks there are systemic inventory 'boom-bust' problems that almost always get transmitted back up such supply chains from one partner to the next. This phenomenon was first documented by Jay Forrester at MIT in the 1960s and is now commonly referred to as the 'Bullwhip' effect in 


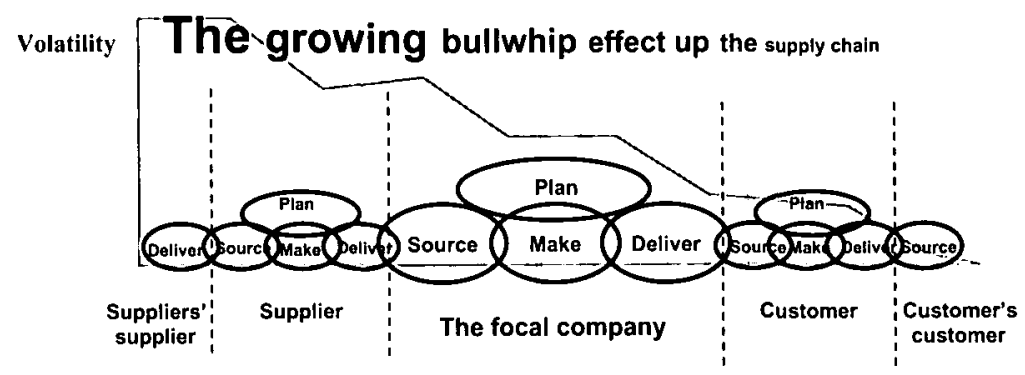

Figure 1. The bullwhip effect in the supply chain

supply chains (Lee, Padmanabhan, \& Whang, 1997a,b; Sterman, 2000). As suggested in Figure 1, the Bullwhip is experienced across supply chains, with the downstream end-customer's growing amplitude having devastating effects on upstream supply chain partners. Among its many causes, the Bullwhip is strongly driven by poor forecasting, long lead times and the batching up of orders before they are sent to the next upstream partner - problems all commonly found in Chinese-North America supply chains.

Frohlich (2008) found a typical Western supply chain is often five or six partners deep including retailers, wholesalers, distributors, manufacturers and suppliers linked together in networks stretching over several thousand miles. Including the transportation companies linking such partners together, that number commonly doubles to approximately a dozen companies all coordinating their efforts to turn raw materials into finished goods and eventually sell them to end-consumers. Of course, the depth of the supply chain depends on the product, but Chinese supply chains are not very different from those in the West except for the greater distances involved. However, in China, the process of cheng bao (subcontracting) was built into the manufacturing process as early as the 1980 s and continues to this day, possibly as a way of fulfilling favours and guanxi obligations (Cooper \& Yinhuo, 1998). Consequently, longer supply chains may occur not for production efficiency, but from a cultural expectation.

Going back to the Bullwhip effect discussed above, greater distances in the supply chains tend to have much longer lead-times across the Pacific, which, of course, make companies plan their orders by the container load(s) around seasonal batch orders, and this all too often leads to poor forecasting. In short, such global supply chains typically have large inventory holding costs along with high associated risks of product damage and obsolescence. Moreover, their sheer length and relatively slow movement of events and inventory make it difficult for partners to monitor and control the actions of their up- and downstream partners in such supply chains. These are problems that are universal and are not unique to Chinese supply chains.

As a result of these inherent inefficiencies, relationships in Chinese supply chains are particularly important. From the Western perspective, for companics offshor- 
ing their supply to China, they want to work with stable, trustworthy partners capable of planning months into the future and holding large quantitics of inventory - especially raw materials. Conversely, from the Chinese supplier's perspective, they are looking for downstream North American partners with access to large consumer markets, dependable forecasts and the ability to pay for and disseminate large amounts of finished goods inventory.

Given the thousands of miles and months of time separating upstream and downstream partners in such supply chains, trust is absolutely critical. This is one reason why relationships in such supply chains are often more powerful than the governments (Chinese or US) that authorize and support such trading. Since the Bullwhip threatens to make everyone lose a lot of money across every single product line imported into the USA from China, upstream suppliers are just as dependent upon their downstream partners as downstream firms are on their upstream sources. In such situations, supply chain contracts typically go to firms based upon past relationships and a firm's actual performance over the previous months and years. US companies evaluate their Chinese suppliers on their ability to produce high quality, low cost products months in advance before actual demand materializes, while Chinese suppliers value their downstream partner's abilities to anticipate consumer trends and sell container loads of electronics, food, toys and countless other items.

In such supply chains, even relatively minor infractions can cause serious tensions between partners. From the Chinese supplier's perspective, a US partner's extended payments or inability to accept large quantities of inventory are reasons for concern. From the US partner's perspective, a Chinese partner's use of questionable raw materials or labour practices is similarly bad - especially for 'branded' products. Trust helps overcome these issues. When up- and downstream partners build a relationship whereby suppliers have little to worry about in terms of demand and retailers are assured of supply, then everyone reaps the benefits in terms of greater stability and resulting profitability.

Creating such trust, however, is often easier said than done. Think for an instant about what many US companies are actually insisting that their Chinese suppliers accomplish: make the same high quality products as would normally be built in North America, only now sell them at a fraction of that cost after transporting them half way around the world by ship, rail and truck. How can this be done? There are only two ways to do so - either Chinese suppliers have to become very progressive in terms of their own manufacturing capabilities and those with whom they partner in their own upstream Asia-wide supply chains, or they can bend the rules and hope that they don't get caught.

In order to ensure quality in their Chinese supply chains, many US companies are increasingly turning to third party assessment of suppliers. In theory these assessors help enforce quality and labour practices across global supply chains, but they tend to catch only the most egregious violators. In short, if an upstream supplier has not bought into the quality and labour standards of its downstream 
partners, then they may take shortcuts. This is especially true given that thirdparty assessors can typically only visit each supplier once or twice a year and the opportunities to bend the rules are always there.

Once again, deep supply chains accentuate these pressures. Picture in your mind a garment supply chain stretching from New York City backwards by long-haul truck to Chicago, then by intermodal rail to Long Beach, container ship to Shanghai and again by truck, rail or barge to inner-China or other parts of Asia - how many opportunities for cheating and duplicity are there in such a flow? Or conversely, what would that $30 \notin$ can of dog food, $\$ 2$ tube of toothpaste, or $\$ 9.99$ remote control toy cost at retail if every step in such supply chains were continually monitored for any and all quality or labour infractions? The answer is likely twice as much or even more than it presently does, which, of course, defeats the whole point of relocating US manufacturing overseas in the first place to take advantage of lower cost labour.

The solution to this seller-buyer trust dilemma (which is always present in supply chains) is 'integration'. Going back to the above points on the Bullwhip effect, this effect is at its worse when lead times are long, forecasts are poor and circumstances make companies batch up their orders before forwarding them on to their next partners as is commonly found in Chinese-US supply chains. Real time point of sale information and planning technologies help global supply chains disseminate information which helps prevent the batching up of orders and mitigates bad forecasts. Likewise, express container ships now regularly sail the Pacific between major Chinese and West Coast harbours crossing in as little as 10 days, depending on the weather (see for example http://www.matson.com/china/index.html).

As another example, open and honest supply chain partners can now expedite products through customs and keep them rapidly moving towards consumers. In the case of international air freight, everyday FedEx and UPS cargo jets leave China bound for the USA with many items on board not yet cleared into the USA through customs. Through the cooperation of all parties together (supplier, buyer, US Customs and the air freight carrier), by the time these planes land 12 hours or so later in the USA, everything is cleared for arrival and ready for immediate delivery.

Similarly, companies like Starbucks are famous for offering their suppliers a higher price per pound for their coffee if such growers can consistently prove that they don't use any child labour or other unethical practices in their production. Not unlike the United States and former Soviet Union's philosophy of 'trust but verify' during the Cold War, Starbuck's policy has helped to create a model of supply chain compliance that is the envy of many other Western businesses. Another famous example of ethical sourcing is $\mathrm{Li} \&$ Fung's most senior managers meeting each and every month and going through every single supplier's most recent quality and labour practices in the numerous supply chains that they operate for over 700 major US companies, including the Gap, Levi's, Old Navy and The Limited.

As these examples suggest, trust can be created in deep supply chains, but only if companies are willing to accept the extra cost and effort. Roth et al. (2008) 
suggest that trust is very important when traceability and transparency are difficult to achieve and the result is a need for firms to invest in long-term relationship building. Nothing is free and there are few, if any, government mandates to do so (except for the threat of product liability lawsuits) and thus only relatively few sets of companies choose to go the distance by building better relationships and spreading 'visibility' across their deep supply chains. Many others, of course, choose to do nothing, perhaps hoping for the best among their supply base but, one might also argue, rather naively ignoring the very costs and quality pressures that they are driving backwards up their supply chains in order to 'pile inventory high and sell it cheap' as Sam Walton once famously described as the key to modern retail.

\section{RESEARCH SUGGESTIONS}

Recent work aims to identify the state of the art of research on supply chains in China (Flynn, 2008; Zhao, Flynn, \& Roth, 2006, 2007b). In this paper, we identify how and when Chinese supply chains can evolve into conflict situations because of intrusions into the supply chain. Our analyses suggest many possible questions for future research. What is the impact of cultural misunderstandings of the goals and objectives of the partner firms? What kind of relationships are developed between the partner firms and which partners are in vs. out? What is the impact of the many levels (depth) of the supply chain? What is the impact of the obsession with 'low cost'? What is the role of guanxi and trust in monitoring the behaviours of suppliers deep in the supply chain?

We speculate about the institutional environment influences on the supply chain, on product quality and on the relationships of the firms involved in the supply chain. We suggest that, in general, the contribution of resources by the foreign partner should be positively related to the performance of the supply chain but that the order qualifiers are not fully understood by the supplier. At the same time, the suppliers are also subject to cultural misunderstanding and misjudgments about the importance of such things as cost vs. quality and the risks involved in illegitimate behaviour. We suggest that trust between the members of the supply chain will depend on mutual perceptions of fairness and reciprocal exchanges. Betrayal of trust may have major consequences such as partner conflict and, sometimes, the consequences go beyond just the organizations involved.

Theory development for studying Chinese supply chain issues may have to borrow from theorics already in use in other contexts (Tsui, 2007; Whetten, 2008). Because many of the issues and research questions about supply chains in China are somewhat unique to the literature and of a sensitive nature, it may be necessary to use novel approaches, to extend the current theories and to make new theoretical contributions. One approach might be to revisit the firms that have been identified as having run into some kind of trouble and, through retrospective research, to reconstruct what happened and why. Because the firms will have been 
already identified publicly, the management may be willing to talk about what happened since there is no longer a risk of being exposed. When such research is conducted by a trusted person, through guanxi, the suppliers may be more willing to share their experiences.

Economic databases may not be helpful for the kind of research questions we are proposing and the empirical work should probably use a mixture of methodologies, especially field interviewing, case studies and site visits. It is always helpful to use some triangulation of data when possible, such as a combination of archival data, interviews and survey data. Most existing supply chain management research focuses on dyads, consisting of a supplier and a customer, or at best triads, consisting of a supplier, manufacturer and customer. However, it is impossible to understand the nuances of deep and complex supply chains by studying supply chain dyads and triads. Instead, it will be desirable to study entire supply chains. This will require new research methodologies, moving beyond surveys to qualitative methods.

There is a great need to understand the nature and the extent of quality problems in deep supply chains that pass through China. Are particular industrics more affected by Chinese supply chain quality issues than others? Do the problems tend to originate in particular regions in China more than others? Are quality problems more likely with state-owned and communally owned plants, than multinationals, joint ventures or privately owned plants? There is a large body of literature on emerging economies that is relevant to this line of research, as well as on unique ownership structures in China.

In particular, there are three areas for future research concerning issues about deep supply chains. The first is creating visibility across such supply chains. Along those lines, how do you create visibility across an entire supply chain that typically' stretches halfway around the world and often involves a dozen or more parties that typically don't even know each other? Similarly, is it best to start downstream at the end-customer level and work backwards upstream creating visibility, or begin upstream and progress back down? How are competitive priorities related to visibility? When US customers send a strong message about price, the Chinese suppliers may incorrectly assume that anything they can do to lower cost is desirable to their customers. This is related to the theoretical literature on competitive priorities and order winners and qualifiers in the operations management literature.

The second area revolves around trust. Not unlike visibility, future research needs to investigate how to create and manage trust in deep supply chains. Given the contractual nature of buying and selling, many partners today in international supply chains maintain an arms distance relationship with their suppliers and customers. What happens when there is a betrayal of trust? What techniques for building relationships and trust are successful across different supply chains? The marketing literature on relationship commitment may be relevant to this line of research (see also Zhao, Huo, Yeung, \& Flynn, 2007a). For example, are deceptive practices more common among instrumental transactional relationships between 
supply chain partners than those characterized by normative relationship commitment? Are there managerial techniques possible that help to minimize the betrayal of trust? How does a supply chain create an atmosphere whereby partners can raise legitimate problems - like quality or labour issues - without voiding pending contracts or jeopardizing future transactions? Not unlike 'whistleblowers' inside a company, in many global supply chains silence concerning problems is typically rewarded with future business while raising such issues with your partner(s) may incur the risk of the company being dropped from the network. This is related to power issues within a supply chain, particularly reward and coercive power. It may also be related to transaction cost economics theory, which suggests that investments in transaction specific assets will provide temptation for the supply chain partner to engage in opportunistic behaviour.

The final area for future research revolves around supply chain depth. How do you reduce the depth of a supply chain? Is there an optimal depth to a supply chain? Do different types of products merit different supply chain depths? What role do foreign partner resources play and what is the role of training and management development? Simulations, in particular, may be able to model supply chains and determine their optimal depth depending on the context and could prove to be very fruitful avenues for such future research. In summary, this is fertile ground for future research that could also have important managerial implications.

\section{CONGLUSION}

Our contribution in this paper is to bring to the forefront a discussion about why supply chains do not always flow through in China and how this may contribute to the product quality problem that exists today in China and beyond. We suggest the type of questions that researchers can conduct to understand this phenomenon better. Carefully designed and conducted research can inform us as to why current solutions are not effective, help us to understand how successful firms address some of these supply chain issues and unveil the factors leading to the problems in supply chains.

\section{REFERENCES}

Batjargal, B. 2007. Comparative social capital: Networks of entrepreneurs and venture capitalists in China and Russia. Management and Organization Revieze, 3: 397-419.

Beamish, P. W., \& Bapuji, H. 2008. Toy recalls and China: Emotion vs. evidence. Management and Organization Review, 4: 197-209.

Buckley, P. J. 2007. The strategy of multinational enterprises in the light of the rise of China. Scandinavian Journal of Management, 23: 107-126.

Chen, X. P., \& Peng, S. 2008. Guanxi dynamics: Shifts in the closeness of ties between Chinesc coworkers. Management and Organization Revieze, 4: 63-80.

Child, J., \& Czeglédy, A. P. 1996. Managerial learning in the transformation of Eastern Europe: Some key issues. Organization Studies, 17: 167-179.

Cooper, E., \& Yinhuo, J. 1998. The artisans and entrepreneurs of dongyang county. Armonk, NY: M.E. Sharp. 
Elangovan, A. R., \& Shapiro, D. L. 1998. Betrayal of trust in organizations. Academy of Management Revieze, 23: 547-566.

Ellram, L. 1990. The supplier selection decision in strategic partnerships. Joumal of Purchasing and Materials Management, 26(4): 8-14.

Flynn, B. B. 2008. Having it all: Rigor versus relcvance in supply chain management rescarch. Journal of Supply Chain Management, 44(2): 63-67.

Frohlich, M. T. 2008. An empirical study of supply chain champions. Working Paper, Indiana University Kelley School of Business. For presentation at Production and Operations Management Society Annual Meeting, La Jolla, May 2008.

Hill, Т. 2000. Manufacturing strategy: Text and cases (3rd ed.). Boston, MA: Irwin McGraw-Hill.

Hofstede, G. 1980. Culture's consequences: International differences in work-related values. Beverly Hills, CA: Sage Publications.

Hosmer, L. T. 1995. Trust: The connecting link between organizational theory and philosophical ethics. Academy of Management Revieze, 20: 379-403.

Jiang, B., \& Prater, E. 2002. Distribution and logistics development in China: The revolution has begun. International Journal of Physical Distribution and Logistics Management, 32: $783-798$.

Lce, D. Y., \& Dawes, P. L. 2005. Guanxi, trust and long-term in orientations in Chinese business markets. Joumal of Intemational Marketing, 13(2): 20-56.

Lee D.J., Pac,J. H., \& Wong, Y. H. 2001. A model of close business relationships in China (guanxi). European Journal of Marketing, 35: 51.

Lee, H. L., Padmanabhan, V., \& Whang, S. 1997a. Information distortion in a supply chain: The bullwhip effect. Management Science, 43: 546-558.

Lec, H. L., Padmanabhan, V., \& Whang, S. 1997b. The bullwhip effect in supply chains. Sloan Management Revieze, Spring: 93-102.

Li, J. H., Anderson, A. R., \& Harrison, R. T. 2003. Total quality management principles and practices in China. International Joumal of Quality and Reliability Management, 20: 1026-2050.

Luo, Y. 2006. Opportunism in inter-firm exchanges in emerging markets. Management and Organization Revieze, 2: 121-147.

Luo, Y. 2008. A strategic analysis of product recalls: The role of moral degradation and organizational control. Management and Organization Revieze, 4: 183-196.

Lyles, M. A. 2008. Transcript of interview with Robert Eckert, CEO and Chairman, Mattel. Business Horizons (in press).

Lyles, M. A., \& Salk, J. 1996. Learning from forcign parents in international joint ventures: An empirical examination in the Hungarian Context. Joumal of Intemational Business Studies, 27: 877-904.

Mavondo, F., \& Rodrigo, E. 2001. The effect of relationship dimensions on interpersonal and interorganizational commitment in organizations conducting business between Australia and China. Journal of Business Research, 52: $111-121$.

Pun, D. T. 2001 . Cultural influences on total quality management adoption in Chinese enterprises: An empirical study. Total Quality Management, 12: 323-342

Rao, A. N., Pcarce, J. L., \& Xin, K. 2005. Governments, reciprocal exchange and trust among business associatcs. Joumal of International Business Studies, 36: 104-1 18.

Ramascshan, B., Yip, L. S. C., \& Pac,J. H. 2006. Powcr, satisfaction, and relationship commitment in Chincse storc-tcnant relationship and their impact on performancc. Joumal of Retailing, 82: $63-70$.

Roth, A. V., Tsay, A. A., Pullman, M. E., \& Gray, J. V. 2008. Unraveling the food supply chain: Strategic insights from China and the 2007 recalls.Journal of Supply Chain Management, 44(1): 22-39.

Sideri, S. 1997. Globalization and regional integration. European Journal of Development Research, 9(1): 38-81.

Stecnsma, K., \& Lyles, M. A. 2000. Explaining IJV survival in a transitional cconomy through social cxchangc and knowledge-based perspectives. Strategic Management Joumal, 21 : 831-852.

Stcensma, K., Barden, J., Dhanaraj, C., Lyles, M., \& Tihanyi, L. 2008. The influence of power, learning, and conflict on the internalization of international joint ventures. Joumal of International Business Studies, 39: 491-508. 
Stcrman, J. 2000. Business dynamics: Systems thinking and modeling for a complex world. New York: McGraw Hill.

Tsui, A. 2007. From homogenizaton to pluralism: International management research in the academy and beyond. Academy of Management Joumal, 50: 1353-1364.

Whetten, D. 2008. Envisioning the systematic practice of contextualized thcory development. Management and Organization Reviewe (in press).

Zamiska, N., \& Fairclough, G. 2008. Drug scare puts China, suppliers under spotlight. Wall Street Journal Asia, 32(115): 1-28.

Zhao, X., Flynn, B. B., \& Roth, A. V. 2006. Decision sciences rescarch in China: A critical review and rescarch agenda - foundations and overview. Decision Sciences, 37; 45 1-497.

Zhao, X., Huo, B., Yeung, J. H. Y., \& Flynn, B. B. 2007a. The impact of power and relationship commitment on integration betwcen manufacturers in a supply chain. Journal of Operations Management (in press).

Zhao, X., Flynn, B. B., \& Roth, A. V. 2007b. Decision Sciences Research in China: Current status, opportunities and propositions for research supply chain management, logistics and quality management. Decision Sciences, 38: 39-80.

Zhou, Y., \& Chuah, K. B. 2002. Computer-integrated manufacturing. China: A report of industrial field survcys. International Journal of Operations and Production Management, 22: $271-288$.

Marjorie A. Lyles (mlyles@iupui.edu) holds the OneAmerica Chair in Business Administration and is Professor of International Strategic Management at the Indiana University Kelley School of Business. Professor Lyles first went to China in 1985 and her research deals with issues about emerging economies. Her primary areas of interest are: emerging economies and internationalization; organizational learning and knowledge transfer; technology management; management of joint ventures and strategic alliances; and China.

Barbara B. Flynn (bbflynn@iupui.edu) is Richard M. and Myra Louise Buskirk Professor of Manufacturing Management and Director, IU Center for International Business Education and Research at the Indiana University Kelley School of Business. She has been actively doing research on manufacturing and supply chains in China. Her primary areas of interest are: world class manufacturing; quality management; just-in-time manufacturing; operations strategy; and innovation management.

Mark T. Frohlich (mfrohlic@iupui.edu) is Associate Professor of Operations Management at the Indiana University Kelley School of Business. He has been doing research on production and operations management issues. He has won best paper awards from the Production and Operations Management Society and the Joumal of Operations Management. His primary areas of interest are: supply chain strategies; e-business; and operations strategy.

Manuscript received: February 25, 2008

Final version accepted: March 17, 2008

Accepted by:

Anne S. Tsui 